\title{
Improved farm tools for women worker to increase productivity and reduce drudgery- An assessment
}

\author{
B. SHARMA, M. GOGOI, A.M. BEGAM, R. BHATTACHARJEE, B. DEKA AND U. GOSWAMI
}

Received: 04.12.2014; Revised: 09.04.2015; Accepted: 24.04.2015

See end of the paper for authors' affiliations

\section{B. DEKA}

Krishi Vigyan Kendra (A.A.U.)

JORHAT (ASSAM) INDIA

Email : babita_s06@yahoo.co.in
ABSTRACT : Agriculture is an important sector where majority of women labour force is engaged and because of using age old tools and implements most of their tasks are tedious monotonous and drudgery prone. Researchers of ICAR institutes effort in introducing various time and energy saving tools to relieve their drudgery in agricultural work has been proven effective in many times. Present study in OFT form is an effort to assess the impact of improved garden tools i.e. Garden rack, Circular blade weeder and hand fork on economic viability and physiological workload of women in comparison with traditional age old tools Kuhrpi and Hoe conducted in 5 districts of Assam comprising 40 beneficiaries and 40 non-beneficiaries. Result revealed that less time required in all selected activities by using improved garden tools resulted less labour cost than simple Hoe and Khurpi. Moreover, differences of energy expenditure (both by using improved garden tools and traditional Kuhrpi and Hoe) in same activities indicates it helps in reducing physiological fatigue. Opinion perceived by farm women of using such tools is highly acceptable than Hoe and Khurpi.

KEY WORDS: Farm tools, Women worker, Productivity, Drudgery

- HOW TO CITE THIS PAPER : Sharma, B., Gogoi, M., Begum, A.M., Bhattacharjee, R., Deka, B. and Goswami, U. (2015). Improved farm tools for women worker to increase productivity and reduce drudgery- An assessment. Asian J. Home Sci., 10 (1) : 144-148. 